\title{
Educação do Campo e políticas públicas no município de Abaetetuba-Pará
}

Rosenildo da Costa Pereira ${ }^{1}$, Antonio Marcos Santos Pureza ${ }^{2}$, Salomão Antonio Mufarrej Hage ${ }^{3 \mathrm{i}}$

${ }^{1}$ Secretaria Municipal de Educação de Abaetetuba - SEMEC. Rua Pedro Rodrigues, 700, Centro, AbaetetubaPA. Brasil. rosenildocosta@bol.com.br. ${ }^{2}$ Secretaria Municipal de Educação de Abaetetuba - SEMEC. ${ }^{3}$ Universidade Federal do Pará - UFPA.

RESUMO. O presente texto aborda as políticas públicas de Educação do Campo, desenvolvidas no Brasil, considerando as especificidades e peculiaridades do município de Abaetetuba, localizado no Estado do Pará. É resultante de um processo de investigação bibliográfica, documental e de campo, com os sujeitos que participam da gestão municipal e do movimento de Educação do campo local. Conclui-se com o estudo que o município em foco encontra-se numa fase inicial de discussão e implementação de políticas voltadas para o atendimento dos sujeitos do campo, tendo os movimentos sociais e instituições de ensino superior locais assumido posição privilegiada como protagonistas nesse processo, como fomentadores de afirmação e implementação de políticas e práticas sintonizadas com as demandas e diversidade sociocultural e territorial local.

Palavras-chave: Educação do Campo, Política Educacional, Movimentos Sociais. 


\title{
Rural Education and public policies in Abaetetuba-Pará
}

\begin{abstract}
The present text addresses the public policies of Rural Education, developed in Brazil, considering the specificities and peculiarities of the Abaetetuba city, located in the State of Pará. It is the result of a bibliographical, documentary and field research process, with the subjects that Participate in municipal management and the local social movement of rural Education. It concludes with the study that the city in focus is in an initial phase of discussion and implementation of policies aimed at the care of the rural people, with local social movements and higher education institutions assuming a privileged position as protagonists in this process, as promoters of affirmation and implementation of policies and practices Linked to the demands and local socio-cultural and territorial diversity.
\end{abstract}

Keywords: Rural Education, Education Policy, Social Movements. 


\section{Educación Rural y las políticas públicas en el municipio de Abaetetuba-Pará}

RESUMEN. Este documento aborda el campo de las políticas públicas de Educación, desarrollado en Brasil, teniendo en cuenta las especificidades y peculiaridades del Municipio de Abaetetuba, ubicada en el estado de Pará. Es el resultado de un proceso de investigación bibliográfica, documental y de campo, con temas participar en la gestión municipal y el movimiento campo de la educación local. Se concluye con el estudio que el municipio en el enfoque en una etapa temprana de la discusión e implementación de políticas para el cuidado de los sujetos del campo, con los movimientos sociales y las instituciones de educación superior locales asumió una posición privilegiada como líderes en este proceso, como promotores de la afirmación y la aplicación de políticas y prácticas en sintonía con las demandas y la diversidad sociocultural y localización territorial.

Palabras clave: Educación del Campo, Política Educacional, Movimientos Sociales. 


\section{Introdução}

A história da educação brasileira tem sido marcada pela exclusão social da maioria da população que, durante muito tempo, foi vista pelo Governo brasileiro como pessoas incapazes de crescer intelectualmente e como trabalhadores, não precisavam de escolarização para desenvolver suas atividades cotidianas nas fábricas, nos engenhos de cana de açúcar, na colheita de café no início da urbanização, situação que influenciou de forma determinante as políticas públicas implementadas no país.

No enfrentamento a esse determinismo, ao longo dos anos os trabalhadores vêm se articulando no sentido de reverter essa dura e perversa realidade por meio de movimentos sociais, no campo e na cidade, e por meio de suas lutas e reivindicações, têm conquistado melhorias no cotidiano socioeducativo dos trabalhadores e trabalhadoras, especialmente no campo no Brasil.

Neste sentido, a Educação do Campo como política pública de inclusão social no Estado brasileiro vem sendo forjada pelas constantes mobilizações dos movimentos sociais, especialmente do campo, com desdobramentos significativos na realidade local, onde moram os sujeitos do campo. Esse ensaio tem o objetivo de explicitar e analisar a maneira como se dá a materialização das políticas de Educação do Campo no Brasil, focando de forma mais específica à realidade do município de Abaetetuba, no Estado do Pará.

As reflexões aqui apresentadas são resultantes de um levantamento bibliográfico, documental e de campo, com sujeitos que participam da gestão da educação pública do município de Abaetetuba e dos movimentos de educação do campo da Região Tocantina, onde o município de Abaetetuba se insere.

O texto está dividido em quatro seções. Inicialmente refletimos sobre a participação dos sujeitos do campo como protagonistas na construção de um projeto político de Educação do Campo. Em seguida, resgatamos aspectos marcantes da história e especificidade do município de Abaetetuba, destacando a realidade da educação local, especialmente no meio rural, apresentando dados estatísticos obtidos junto à Secretaria Municipal de Educação (SEMEC). Damos sequência com a articulação dos movimentos sociais para a emergência do debate político sobre Educação do Campo em Abaetetuba e finalizamos com as considerações finais acerca da temática em estudo.

Os sujeitos do campo como protagonistas na construção de uma política de educação do campo 
As populações do campo foram historicamente excluídas das políticas públicas de educação implementadas pelo Governo brasileiro, uma vez que prevalecia uma compreensão generalizada de que para viver e trabalhar no campo não era necessária à educação escolar.

Leite (1999) deixa claro essa exclusão por parte do Poder Público ao revelar que as Constituições Brasileiras de 1824 a 1988 não mencionaram em nenhum momento a questão da educação rural, apesar de vivermos em um país considerado eminentemente de origem agrário exportador.

Tendo em vista a ausência de políticas públicas educacionais para o campo e reconhecendo a importância da educação escolar como forma de construção da cidadania humana, os sujeitos do campo se organizaram, principalmente por meio de movimentos sociais para cobrar a dívida histórica do Estado quanto ao seu papel de fomentador de políticas públicas sociais e educacionais de atendimento às populações do campo.

Para Silva (2004) até meados dos anos de 1960, uma pequena parcela da sociedade brasileira frequentava a escola, evidenciando que a educação era privilégio da classe burguesa. A partir desse período a classe trabalhadora brasileira passou a pressionar o Estado, exigindo escolas para seus filhos. O Estado "atendeu" a solicitação dos trabalhadores, mas o perfil das escolas construídas seguia os mesmos princípios da educação burguesa e com características urbanocêntricas, ignorando o saber popular, por considerá-lo um saber que precisa ser revisto, aperfeiçoado e até mesmo extinto, uma vez que o saber científico é o que deve prevalecer para se ter prestígio e ascensão social.

Segundo Bagno (2007, p. 31) a luta histórica das classes populares por educação é resultado da pressão de amplas camadas sociais que haviam ficado excluídas do processo de escolarização, por estarem fora das zonas urbanas, e começaram a exigir que seus filhos e filhas, já nascidos e criados nas cidades, tivessem acesso à educação. Foi essa pressão social que ocasionou a “democratização" do ensino, quer dizer, o vertiginoso aumento do número de salas de aulas em todo o Brasil, mas, sobretudo nas grandes aglomerações urbanas.

Nesse sentido, a escola ofertada não foi feita para atender à expectativa das classes populares, como bem diz Soares "a escola que seria para o povo é, na verdade, contra o povo". (2002, p. 10). Ou seja, não foi uma escola pensada levando em consideração os valores culturais das classes populares. Era uma escola 
excludente que desconsiderou os modos de vida e de trabalho das classes trabalhadoras brasileiras, principalmente dos trabalhadores e trabalhadoras do campo.

Os sujeitos do campo têm se mostrado insatisfeitos com as políticas educacionais e com o modelo de educação projetados pelo Governo brasileiro para o território do campo, e se mobilizam cobrando do Poder Público, por meio de reivindicações, uma atuação mais efetiva quanto à efetivação de um projeto político educacional voltado para atender às demandas e necessidades de uma educação sintonizada com a realidade de vida e diversidade sociocultural e territorial do campo.

Para Gomes, Silva e Wanzeler (2007, p. 116):

A educação do campo a que nos referimos é um movimento que vem sendo construído gradativamente ao longo do tempo, principalmente pelas entidades da sociedade civil e vem tendo como os principais protagonistas os movimentos sociais que acreditam que a educação desses sujeitos deve estar relacionada ao processo de luta e emancipação que vise à construção de um ser humano crítico e politicamente ativo, capaz de reconhecer e se (re)conhecer como sujeito integrante do campo, fazendo com que esta educação não seja mais um modelo de ensino imposto, atrelada ao modelo urbano de ensino, que pouco valoriza o real contexto histórico do indivíduo e não aponta caminhos para que ele veja que, o campo, também é lugar de construção de educação.

A luta por educação e por escola tem sido uma bandeira de luta incessante dos trabalhadores e trabalhadoras do campo por entender que o campo só se desenvolverá dignamente se tiver assegurado aos sujeitos que nele vivem uma educação pública de qualidade social e que seja efetivamente do campo, vinculada à identidade e ao cotidiano de seus sujeitos através do desenvolvimento de uma prática educativa emancipatória.

As mobilizações por uma educação do campo iniciaram a partir de julho de 1997 quando foi organizado o I Encontro de Educadoras e Educadores da Reforma Agrária (ENERA), tendo como protagonista o movimento dos Trabalhadores Rurais Sem Terras (MST) em parceria com diversos Órgãos Governamentais e não Governamentais, Instituições de Ensino e Pesquisa dos quais se encontravam representantes das seguintes entidades: Universidade de Brasília (UnB), Conferência Nacional dos Bispos do Brasil (CNBB), Fundo das Nações Unidas para a Infância (UNICEF) e Organização das Nações Unidas para a Educação, Ciência e Cultura (UNESCO). $\mathrm{O}$ encontro teve como objetivo promover um debate com um olhar voltado para a educação do campo e para a construção de 
uma proposta política de educação que respeite o território em que se encontram os sujeitos do campo (Arroyo, Caldart \& Molina, 2004).

As discussões promovidas no I ENERA provocaram a inserção do debate sobre a Educação do Campo na agenda das políticas públicas em 1998 por ocasião da Primeira Conferência por uma Educação Básica do Campo, realizada em Luziânia no Estado de Goiás. Como Caldart (2004, p. 15) explicita,

\begin{abstract}
$\mathrm{Na} 1^{\text {a }}$ Conferência reafirmamos que o campo é espaço de vida digna e que é legítima a luta por políticas específicas e por um projeto educativo próprio para seus sujeitos. Também foram denunciados os graves problemas de falta de acesso e de baixa qualidade da educação pública destinada à população trabalhadora do campo. Discutimos propostas e socializamos experiências de resistência no campo e de afirmação de outro projeto de educação.
\end{abstract}

Nesse sentido, depreende-se que a longa trajetória de luta dos trabalhadores do campo tem promovido o debate e, sobretudo, a construção de uma proposta política de educação própria para o campo. A Educação do Campo na realidade brasileira vem sendo construída pelos sujeitos do campo que continuamente vêm lutando por uma educação mais justa, igualitária e de qualidade social para o campo que afirme a diversidade que o constitui.

$$
\text { O conceito de Educação do Campo }
$$

foi legitimado na realidade brasileira no ano de 2002 com a aprovação das Diretrizes Operacionais para a Educação Básica nas Escolas do Campo. Considerada até então como um marco histórico para um país que, durante muito tempo, excluiu a maioria de seu povo dos bens essenciais à vida, entre os quais citamos a educação. Essas Diretrizes resultam das mobilizações dos movimentos sociais do campo, organizados por meio da Articulação Nacional Por uma Educação do Campo, demonstrando que, aos poucos, os sujeitos do campo vêm conquistando seu espaço enquanto coletivo social.

Em função dessas mobilizações é que foi instituída pelo Ministério da Educação em 2008 a Resolução $N^{o}$ 2, de 28 de Abril de 2008 que "Estabelece diretrizes complementares, normas e princípios para o desenvolvimento de políticas públicas de atendimento da educação Básica do Campo".

Essas mobilizações obtiveram outras conquistas no campo da legislação, como: Resolução CNE/CEB n ${ }^{\circ}$ 2/2008 - que estabelece diretrizes complementares, normas e princípios para o desenvolvimento de políticas públicas de atendimento da educação Básica do 
Campo; Parecer CNE/CEB n ${ }^{\circ}$ 1/2006 que reconhece os Dias Letivos da Alternância; Resolução CNE/CEB $n^{\circ}$ 4/2010 - reconhece a Educação do Campo como modalidade de Educação Básica e define a identidade da Escola do Campo; Decreto $\mathrm{n}^{\circ} 7.352 / 2010$ - que dispõe sobre a Política Nacional de Educação do Campo e sobre o Programa Nacional de Educação na Reforma Agrária (Pronera); e a Lei $n^{\circ}$ 12.960/2014 - que exige manifestação de órgão normativo do sistema de ensino e da comunidade escolar para o fechamento de escolas do campo, indígenas e quilombolas.

Os instrumentos jurídicos listados são importantes para o fortalecimento da luta pelo direito à educação dos povos do campo, no entanto, o Decreto de $\mathrm{n}^{\circ}$ 7.352/2010 merece ser destacado por atribuir à Educação do Campo a condição potencial de política de Estado, ao estabelecer que a política de Educação do Campo destina-se à ampliação e qualificação da oferta de educação básica e superior às populações que vivem nos territórios rurais, e que sua oferta deve ser de responsabilidade compartilhada entre todos os entes federados.

Molina e Freitas (2011) também ressaltam a importância do Decreto de 2010 pelo fato de afirmar o reconhecimento jurídico do direito à educação e da obrigatoriedade do Estado em promover intervenções que atentem para as especificidades necessárias ao cumprimento e garantia desses direitos; constituindo-se num instrumento de pressão e negociação junto aos poderes públicos, nas instâncias federal, estadual e municipal para a ampliação da ofertada de educação aos povos do campo.

O protagonismo dos movimentos sociais na definição dos marcos regulatórios explicitados impacta na criação e implementação de projetos e programas voltados aos povos do campo e que afirmam sua diversidade sociocultural e territorial, tais como: Programa Nacional de Educação na Reforma Agrária PRONERA - oferece escolarização aos jovens e adultos beneficiários dos projetos de assentamento criados ou reconhecidos pelo Instituto Nacional de Colonização e Reforma Agrária - INCRA, em todos os níveis de ensino; PROJOVEM Campo Saberes da Terra - oferece escolarização aos agricultores de 18 a 29 anos que não concluíram o Ensino Fundamental. Programa de Apoio à Formação Superior em Licenciatura em Educação no Campo - PROCAMPO - oferece o curso de Licenciatura em Educação do Campo nas IES públicas, voltados à formação de educadores dos anos finais do Ensino Fundamental e do Ensino Médio nas 
escolas rurais; Programa Escola da Terra - oferece formação continuada de docentes das escolas multisseriadas rurais $\mathrm{e}$ quilombolas, com a utilização da Pedagogia da Alternância; Programa Nacional de Educação do Campo PRONACAMPO - conjunto de ações articuladas com o objetivo de apoiar técnica e financeiramente os Estados, Distrito Federal e Municípios na implementação da política de Educação do Campo, visando ampliar o acesso e a qualificação da oferta da educação básica e superior aos sujeitos do campo.

Esses programas são implementados pelo Ministério da Educação e pelo Ministério do Desenvolvimento Agrário por meio da articulação entre os órgãos públicos federais, estaduais e municipais, as universidades e as organizações e movimentos sociais populares do campo. Eles têm assumido o desafio de pautar as especificidades socioculturais e territoriais nas políticas públicas que chegam às escolas do meio rural.

Essas conquistas todas implicam em desdobramentos em nível nacional, regional e estadual com efeitos positivos nos territórios rurais, onde os assentados da reforma agrária e as populações tradicionais do município de Abaetetuba têm usufruído das conquistas obtidas pelos movimentos sociais do campo em termos de educação superior pública para o campo.

O Estado do Pará, onde o município de Abaetetuba se insere, é um dos pioneiros em pesquisa em educação do campo. Na Universidade Federal do Pará encontram-se o Grupo de Estudo e Pesquisa em Educação do Campo na Amazônia (GEPERUAZ) e o Grupo de Estudo e Pesquisa em Educação do Campo na Região Tocantina (GEPECART), entre muitos outros, que desde 2002 vêm desenvolvendo estudos e pesquisas em educação do campo na Amazônia Paraense (Hage, 2005).

A criação e consolidação desses grupos de pesquisas foram importantes para a criação do Fórum Paraense de Educação do Campo (FPEC) que, segundo Hage (2005, p. 25), agrega

...entidades da sociedade civil, movimentos sociais, instituições de ensino, pesquisa, órgãos governamentais de fomento ao desenvolvimento e da área educacional da sociedade paraense, que compartilhando princípios, valores e concepções políticopedagógicas buscam defender, implementar, apoiar e fortalecer políticas públicas, estratégias e experiências de educação do campo e desenvolvimento rural com qualidade social para todos/as cidadãos/ãs paraenses, sobretudo para as populações do campo, aqui entendidas como: agricultores/as familiares, indígenas, quilombolas, extrativistas, ribeirinhos e pescadores (FPECDR, 2004). 
Na caminhada do FPEC são marcos importantes: o I, II, III e IV Seminário Estadual de Educação do Campo e o I e o II Seminário Estadual de Juventude do Campo, realizados entre 2004 a 2010; o I e o II Encontro de Pesquisa em Educação do Campo do Estado do Pará, realizados em 2008 e 2010 no Pará; o I Seminário Estadual das Licenciaturas em Educação do Campo do Pará e Amapá e III Encontro de Pesquisa em Educação do Campo, realizados em 2012; o IV Encontro Nacional dos Cursos de Licenciatura em Educação do Campo, em 2014, e as plenárias realizadas pelo FPEC, onde se reflete e se planeja a intervenção em questões específicas demandadas pelos seus integrantes.

Nesses eventos se reúnem um número ampliado de sujeitos, instituições públicas, movimentos sociais e entidades não governamentais com a intenção de incidir nos processos de formulação, implementação, acompanhamento e controle social de políticas e práticas educacionais sintonizadas com a realidade do campo, constituindo-se em espaços de circulação de depoimentos, insatisfações, aspirações, reivindicações e expressam e compartilham a educação que se pretende que seja assegurada nas escolas do campo.

Focando o município de Abaetetuba propriamente, Pereira e Pereira (2010, p.
45) destacam o ensino superior para os filhos dos agricultores Abaetetubenses, onde o Curso de "Pedagogia das Águas" ofertado entre os anos de 2006 e 2010 pelo PRONERA no Campus Universitário de Abaetetuba da Universidade Federal do Pará (UFPA) constitui-se numa experiência singular. $\mathrm{O}$ Curso de Licenciatura Plena em Educação do Campo, presente em inúmeras universidades públicas brasileiras, também chega ao Campus Universitário de Abaetetuba (UFPA) no ano de 2011, por meio do PROCAMPO.

Os cursos de nível superior, quando oferecidos pelo PRONERA em parceria com o Instituto Nacional de Colonização da Reforma Agrária (INCRA), são destinados para assentados da reforma agrária e populações agroextrativistas em que se incluem: ribeirinhos, quilombolas, caiçaras, agricultores familiares, pescadores artesanais, dentre outros (Brasil, 2010). No conjunto, todas essas experiências vêm contribuindo para a emergência, nos últimos anos, de uma nova fase no campo da educação brasileira. Trata-se do paradigma da Educação do Campo que, segundo Caldart (2004, p. 149-150), visa

... a luta do povo do campo por políticas públicas que garantam o seu direito à educação e a uma educação 
que seja no e do campo. No: o povo tem direito a ser educado no lugar onde vive; Do: o povo tem direito a uma educação pensada desde o seu lugar e com a sua participação, vinculada a sua cultura e às suas necessidades humanas e sociais.

\section{E acrescenta mais adiante:}

Trata-se de uma educação dos e não para os sujeitos do campo. Feita sim através de políticas públicas, mas construídas com os próprios sujeitos dos direitos que as exigem. A afirmação deste traço que vem desenhando nossa identidade é especialmente importante se levarmos em conta que, na história do Brasil, toda vez que houve alguma sinalização de política educacional ou de projeto pedagógico específico, isto foi feito para o meio rural $\mathrm{e}$ muito poucas vezes com os sujeitos do campo (Caldart, 2004, p. 151).

Caldart é oportuna ao afirmar que a educação para as populações do campo tem que ser do e no campo, construída na dimensão do debate entre poder público, sujeitos do campo e sociedade civil em geral, em que apresenta visível o modelo político educacional proposto e pensado na dinâmica social do povo camponês, "buscando dar vez e voz para uma parcela da sociedade brasileira que tem ainda muito sua voz silenciada”. (Canali, 2007, p. 16).

Neste sentido, com princípios coerentes e condizentes com a realidade em que estão inseridos, Hage (2005, p. 2) acrescenta que "as populações do campo tem o direito de definir seus próprios caminhos, suas intencionalidades e seus horizontes". Para isso, se faz necessário engendrar a discussão com todos os sujeitos do processo educacional, de modo particular com os sujeitos do campo.

\section{O município de Abaetetuba, aspectos históricos e configuração da educação local}

A história do surgimento do município de Abaetetuba está associada com a sesmaria ${ }^{\mathrm{ii}}$ cedida pelo Rei de Portugal a Francisco de Azevedo Monteiro, local onde este inicialmente demarcou e ergueu o "Povoado de Nossa Senhora da Conceição de Abaeté". (Machado, 2008, p. 13).

Ao longo dos anos Abaetetuba teve diferentes denominações como: Abaeté, Abaeté do Tocantins, enfim, mas o nome definitivo e original do município só foi consolidado em meados dos anos de 1943, passando desde então a ser chamado de Abaetetuba, expressão originária do Tupi Guarani, que significa "lugar de muitos homens ilustres e verdadeiros". (Machado, 2008, p. 14).

O município de Abaetetuba encontrase localizado na região do Baixo Tocantins, limitando-se geograficamente com os municípios de Barcarena, IgarapéMiri, Mojú, Limoeiro do Ajaru e Acará. 
Segundo dados do IBGE de 2010, Abaetetuba possui uma população de 141 mil e 100 habitantes, dos quais 58.102 residem no campo e 82.998 na área urbana. Integra seu terrítório o centro urbano da cidade de Abaetetuba, o distrito de Vila de Beja, ramais, estradas e ilhas num total de 72, situadas na zona Guajarina, à margem direita da foz do rio Tocantins.

Os rios são as principais vias de acesso dos moradores rurais ribeirinhos à sede do município. Segundo Barros (2009, p. 154), "Vários rios estão inseridos na hidrografia do município, são eles: Tocantins, Maratauíra, Arapapu, Acaraqui, Piquiarana, Tucumanduba, Caripetuba, Xingu, dentre outros. A maioria é navegável" e os principais meios de transportes são as rabetas, canoas, rabudos e barcos.

Nestes últimos 10 anos, a cidade de Abaetetuba passou por inúmeras transformações decorrentes da implantação de grandes projetos na região, entre os quais, citamos a Alumínio Brasileiro (ALBRAS), que anunciava trazer o progresso para a região, mas que na prática trouxe situações inúmeras conflitantes, que resultam na expulsão das populações rurais, inchando a sede do município, como cita Jorge Machado (2008, p. 33): deram adeus a jiraus e xerimbabos e instalaram-se na cidade em busca de uma vida melhor, escola para os filhos, televisão nova e geladeira; coisas que o dinheiro da fábrica prometia. Parecia que o progresso e a modernidade eram coisas afinal inevitáveis e viriam para todos. Ledo engano. Com o início da operacionalização da fábrica, os "peões" foram dispensados e muitos ficaram na cidade, engrossando $\mathrm{o}$ contingente de moradores sem emprego ou vivendo de biscates ${ }^{\text {iii }}$.

O então progresso que muitos esperavam resumiu-se na exclusão social da maioria da população aos bens essenciais a sua reprodução humana. O desemprego aumentou e o difícil acesso aos bens materiais e imateriais como: alimentação, eletrodomésticos, roupas, calçados, dentre outros, intensificou a concentração da população nas periferias da sede do município, promovendo o aumento da violência cada vez mais na região Tocantina, especificamente na cidade de Abaetetuba.

Diversos são os meios de produção desenvolvidos no município, que tem sua economia, segundo Barros (2009, p. 154), "baseada, principalmente, nas atividades da pesca, no extrativismo, sobretudo do açaí, e na agricultura", evidenciando a diversidade sócio-produtiva e territorial e a importância das populações rurais para o desenvolvimento local. 
A população de Abaetetuba possui característica cultural e tradicional fortemente marcada pelo aspecto religioso, que se expressa por meio de diferentes seguimentos, como: igreja católica (Nossa Senhora da Conceição, Nossa Senhora de Nazaré, etc.); igrejas pentecostais e neo pentecostais (Assembléia de Deus, Igreja Cristã Evangélica, Igreja Quadrangular, etc.); os Mórmons; entre outros. Tomando a igreja católica como exemplo, é marcante a fé e devoção que os moradores manifestam à sua padroeira Nossa Senhora da Conceição de Abaeté, saindo às ruas da cidade anualmente para prestarem diferentes formas de homenagens e agradecendo à Santa pelos bens alcançados, com sacrifícios no momento do círio e também com as representações de casas e outros objetos, demonstrando uma espécie de bens, conquistados pelo pedido que fizeram à Imagem da Santa.

Abaetetuba se destaca, portanto, por abrigar uma ampla e peculiar diversidade cultural, o que segundo o Dicionário da Educação do Campo, diz respeito à presença de "valores, costumes, formas de vida e sistemas culturais locais, e suas expressões nas formas de trabalho, produção, culinária, música, ritos, religiosidade, etc". (Gorgen, 2012, p. 58).

Como parte da diversidade cultural local, destacamos enquanto movimentos culturais: as festas juninas, que se realizam no Ginásio Hildo Tavares Carvalho, concentrando grande parte da população para sua apreciação; a Tiração de Reis que ocorre no mês de dezembro e faz alusão ao nascimento de Jesus, adaptado por um grupo folclórico local; o carnaval de Abaetetuba, realizado no mês de fevereiro, que motiva a alegria de milhares de brincantes e o Miritifest, evento que atrai um grande número de turistas para a cidade.

Sobre o Miritifest, convém esclarecer que é um evento anual que ocorre no mês de maio ou junho, período em que os artesãos locais se reunem para expor suas produções oriundas de brinquedos produzidos a partir da palmeira do miriti, tais como: barcos, canoas, rabetas, casas e animais como: cachorro, galo, pato, onça, papagio, dentre outros, que são bastante apreciados pelos moradores locais e turistas. O evento é grandioso e faz com que a cidade de Abaetetuba seja reconhecida mundialmente como a capital mundial do brinquedo de miriti, face à criatividade dos artesãos para mostrar a beleza e as peculiaridades da cidade.

Nas ilhas de Abaetetuba as lendas predominam e continuam vivas, sendo repassadas de geração a geração, por moradores ribeirinhos, que em determinadas situações inovam alguns 
aspectos no enredo das estórias, porém prevalecendo sua essência. Algumas dessas lendas como: o Poço da Moça, "Lobisomem", a Lenda da Cobra Grande e etc., são relacionadas diretamente a uma determinada comunidade, ou seja, o fato (enredo) só ocorre em um lugar específico, enquanto outras lendas ocorrem em diversas comunidades do município.

Em termos da oferta da educação, o município de Abaetetuba conta com um número total de 170 escolas, sendo assim distribuídas: 41 na sede, 83 nas ilhas e 46 nas estradas e ramais (SEMEC, 2012).

Dados atuais obtidos junto à Secretaria Municipal de Educação do município no que concerne à matrícula inicial de 2012 evidencia a necessidade de uma atenção especial à Educação do Campo, pois do contingente total de 24.933 alunos matriculados em creche, pré-escola, ensino fundamental e Educação de Jovens e Adultos (EJA) no sistema de ensino municipal, 13.410 estão matriculados nas escolas do campo, num universo de 1.266 turmas, sendo 216 multisseriadas e localizadas nas ilhas, estradas e ramais; e 11.523 se encontram matriculados na sede do município. O município apresenta um quadro composto de 1.327 profissionais docentes atuando na área urbana e na rural.
O universo educacional Abaetetubense apresenta múltiplas especificidades em relação à educação. $\mathrm{Na}$ área urbana as escolas e turmas são seriadas enquanto no meio rural predominam as escolas e turmas multisseriadas e o educador precisa de uma formação específica para que em seu trabalho ele possa organizar atividades para alunos com diferentes níveis de escolarização, idades, ritmos de aprendizagem, etc.

Segundo Brito (2005, p. 4) as turmas multisseriadas são,

aquelas organizadas por diferentes séries e alunos, mediadas por apenas um professor em sala de aula. O professor regente da turma convive com um trabalho que converge diferentes níveis de desenvolvimento, de aprendizagem e singularidades de alunos que se distanciam uns dos outros, construindo assim, tessituras de saberes que contribuirão para o fazer educativo. Saberes necessários para a construção de uma educação voltada para a construção de sujeitos autônomos.

Além dessa situação, nos territórios rurais do município de Abaetetuba, como nos demais municípios paraenses, identificamos problemas de diversas naturezas, que interferem no processo de ensino-aprendizagem dos sujeitos do campo, dentre os quais mencionamos: a ampliação da política de nucleação das escolas, que obriga os estudantes a se 
deslocarem de suas comunidades de origem para acessar a escola em outra comunidade rural ou, predominantemente, na sede dos municípios; calendário escolar que não respeita $\mathrm{o}$ período de safra $\mathrm{e}$ colheita dos sujeitos das comunidades rurais; escola de difícil acesso para muitos educandos que moram em furos e igarapés; professores angustiados ao trabalhar com turmas multisseriadas, na sua maioria com contratos temporários de trabalho, assumindo múltiplas funções na escola além da docência, e lecionando em escolas precárias, que funcionam em barracões, salões de festa e casas de moradores cedidas ou até mesmo alugadas, que não oferecem condições dignas de aprendizagem.

Hage (2005), em seus estudos sobre as escolas rurais multisseriadas tem constatado a presença de um paradoxo que se manifesta na dinâmica dessas escolas, que em um aspecto mais evidente, ressaltamos o quadro dramático de precarização e abandono em que as escolas se encontram, reflexo do descaso com que tem sido tratada a escolarização obrigatória ofertada às populações do campo; e com isso, na maioria dos casos, negligenciamos as possibilidades e propostas construídas por educadores, gestores e sujeitos do campo, no cotidiano das ações educativas dessas escolas, que evidenciam situações criativas e inovadoras que desafiam as condições adversas que configuram a realidade existencial dessas escolas.

Para o autor, a existência desse paradoxo constitui uma referência importante para a formulação de políticas e práticas a serem implementadas na oferta da escolarização aos sujeitos do campo, na medida em que ele ajuda a compreender as contradições que se evidenciam na relação entre a precarização que configura a vida, o trabalho e a educação nos territórios rurais brasileiros e o protagonismo dos professores e professoras do campo, que com suas práticas educativas incidem de forma positiva no cotidiano das atividades da escola (Hage, 2005).

A presença das escolas multisseriadas no município também são uma expressão da heterogeneidade de sujeitos que se fazem presentes nas escolas e nos territórios do campo abaetetubense, uma vez que sua população é constituída por: quilombolas, extrativistas, pescadores, ribeirinhos, assentados, agricultores familiares e moradores da própria sede do município.

$$
\text { Marques (1992, p. 144-145) }
$$
investigando sobre $\mathrm{o}$ profissional da educação cita que "a sala de aula comporta uma pluralidade de sentidos, tanto para quem dela participa, como para quem de fora a observa ... como micro-universo de 
relações complexas, lugar de encontro e da atuação de grupos diversos e pluralmente correlacionados". Do que se depreende, que o espaço escolar Abaetetubense convive com uma ampla e rica diversidade de saberes que resultam do encontro de culturas e de vivências que se estabelecem na prática cotidiana das relações sociais, os quais move o processo de ensino aprendizagem no meio rural e urbano.

\section{Políticas públicas de educação do campo desenvolvidas pela secretaria municipal de educação de Abaetetuba}

As políticas públicas no Brasil emergem dos debates e discussões feitas em âmbito do poder público e com a participação da sociedade civil representada pelos parlamentares eleitos pelo povo. Teixeira (1998, p. 1), ao conceituar políticas públicas, define como sendo um conjunto de

... diretrizes, princípios norteadores de ação do poder público; regras e procedimentos para as relações entre poder público e sociedade ... São, nesse caso, políticas explicitadas, sistematizadas ou formuladas em documentos (Leis, programas, linhas de financiamentos) que orientam um conjunto integrado de ações e decisões articuladas que, normalmente, envolvem aplicações de recursos públicos e afetam positiva e negativamente a população ou alguns setores sociais.
No caso do Brasil, dois tipos de políticas públicas têm sido implementadas pelo Estado, em suas várias esferas federal, estadual e municipal: políticas de Governo, constituídas por meio de programas sociais, sem efeito de legalidade jurídica, podendo ou não ter continuidade com a troca de um governo por outro; e políticas de Estado, que possuem respaldo jurídico visto que foram aprovadas e sancionadas pelos agentes próprios para esse fim, e qualquer governo que assuma a dirigência política tem a obrigação de implementálas.

Oliveira (2011, p. 329) com seus estudos nos ajuda a compreender melhor a distinção entre essas políticas, ao considerar as políticas de governo como aquelas que o Executivo decide num processo elementar de formulação e implementação de determinadas medidas e programas, visando responder as demandas da agenda política interna, ainda que envolvam escolhas complexas; $\mathrm{e}$ as políticas de Estado, como:

aquelas que envolvem mais de uma agência do Estado, passando em geral pelo Parlamento ou por instâncias diversas de discussão, resultando em mudanças de outras normas ou disposições preexistentes, com incidência em setores mais amplos da sociedade (Oliveira, 2011, p. 329). 
Em se tratando do município de Abaetetuba, constatou-se com a realização desse estudo que até o ano de 2009, a Administração pública local não havia implementado políticas específicas de educação do campo. As ações que dizem respeito à educação sempre foram efetivadas no município levando-se em consideração o que determina a nossa lei maior sobre a obrigatoriedade da educação. Conforme está prescrito na exigência do Artigo 211, Inciso $4^{\circ}$ da atual Constituição Federal Brasileira, "na organização de seus sistemas de ensino, os Estados e os Municípios definirão formas de colaboração, de modo a assegurar a universalização do ensino obrigatório". Não havia, portanto, atividades educacionais previstas especificamente para o meio rural, de forma explícita.

Em nossos levantamentos, identificamos o início de implementação de ações de Educação do Campo enquanto política pública no município de Abaetetuba a partir do ano de 2010 com a criação de uma Coordenação específica dentro da Secretaria Municipal de Educação (SEMEC) para atender as demandas específicas das populações do campo local.

Trata-se da Coordenação de Educação do Campo, criada em meio a diversas discussões realizadas no âmbito do Fórum Regional de Educação do Campo-Tocantina II (FORECAT), que reúne os seguintes atores e coletivos sociais: Movimento dos Ribeirinhos e Ribeirinhas das Ilhas e Várzeas de Abaetetuba (MORIVA), Sindicato dos Trabalhadores e Trabalhadoras Rurais de Abaetetuba (STTR), Sindicato dos Trabalhadores em Educação Pública do Estado do Pará (SINTEPP) Sub-Sede Abaetetuba, Associação dos Moradores das Ilhas de Abaetetuba (AMIA); Instituições de Ensino Superior como: Instituto Federal de Educação, Ciência e Tecnologia do Estado do Pará (IFPA - Campus de Abaetetuba), Universidade Federal do Pará (UFPA) Campus de Abaetetuba e representantes do Grupo de Estudo, Pesquisa e Extensão Sociedade, Estado e Educação: Ênfase nos Governos Municipais e Educação do Campo (GEPESEED-UFPA).

$\mathrm{O}$ estudo realizado evidenciou que os movimentos sociais e as Instituições de Ensino Superior participantes do FORECAT foram os principais fomentadores do debate sobre a Educação do Campo, inconformados com a ausência de um projeto político específico de educação para os sujeitos do campo na Região do Baixo Tocantins, começaram a se sensibilizar e mobilizar o poder público da região, especialmente as secretarias de 
educação dos municípios de Acará, Abaetetuba, Mojú, Igarapé-Miri e Barcarena para discutir e implementar políticas públicas específicas de Educação do Campo.

Segundo Canali (2007, p. 17):

É necessário fazer referência à memória de ações e mobilizações de pessoas, professores\as, instituições ... prefeituras municipais e movimentos sociais, que lutam, juntamente com os sujeitos do campo, na defesa da garantia de direitos humanos, especialmente no que diz respeito ao direito à educação, em sua continuidade de estudos com qualificação no campo e para o campo.

O FORECAT foi criado em fevereiro de 2007 pelos movimentos sociais, instituições de ensino superior e pesquisa e secretarias de educação dos municípios do Baixo Tocantins como já foi citado, com o apoio do fórum paraense de Educação do Campo, e desde sua criação tem promovido vários eventos na área da Educação do Campo, envolvendo participantes dos municípios da Região Tocantina, onde o município de Abaetetuba se insere.

Nos dias 26 e 27 de maio de 2007, o FORECAT promoveu o I seminário de Educação do Campo, realizado no município de Igarapé-Miri, com a discussão da temática "Educação do Campo: Saberes e Perspectivas no Baixo
Tocantins" (Ferreira et al, 2010). Em outubro de 2009, realizou-se II Seminário de Educação do Campo do Baixo Tocantins, no município de Mojú, com o objetivo discutir segundo Ferreira et al (2010) o "Desenvolvimento Agrário e as Políticas Públicas em Educação do Campo".

Nos dias 04 e 05 de maio de 2012, o FORECAT promoveu o III Seminário de Educação do Campo da Região Tocantina II sediado no município de Abaetetuba, no auditório da Universidade Federal do Pará (UFPA) - Campus de Abaetetuba. O evento teve como objetivo discutir políticas públicas para região do campo do Baixo Tocantins, com o tema "Das ações dos Movimentos Sociais à institucionalização da Política e a construção de projetos para a Educação do Campo".

A realização desses eventos, a partir da criação do FORECAT, constitui um marco importante para a mobilização da população da Região Tocantina para a um debate mais efetivo de propostas de políticas e práticas de educação do campo, incentivando e pressionando as secretarias de educação locais a criarem coordenações de educação do campo para o acompanhamento das escolas do campo e para implementação de políticas específicas para os territórios rurais. 
No caso específico do município de Abaetetuba, as políticas e atividades desenvolvidas pela Coordenação de Educação do Campo, a partir da criação do FORECAT e realização dos eventos mencionnados, estão voltadas para os povos do campo, das águas e da floresta, dando ênfase aos direitos que lhes são próprios e já se encontram assegurados nas legislações educacionais vigentes. As populações do campo detêm muitos conhecimentos do meio social onde vivem e é possível incorporá-los ao processo de ensino e aprendizagem, dando assim maior evidência às expectativas dos sujeitos do campo enquanto sujeitos de direito, atuantes e protagonistas de sua própria história educativa.

No ano de 2011, outro marco histórico se manifestou na área da Educação do Campo no município de Abaetetuba, por ocasião da plenária para a discussão do Plano Municipal de Educação (PME) com os mesmos representantes das entidades que compõem o FORECAT, e com a participação da sociedade civil em geral. Na pauta da discussão incluiu-se a Educação do Campo com questão específica; o que resultou na inclusão da Educação do Campo como uma das modalidades de Ensino, no artigo VI da Conferência Municipal de Educação para Aprovação do Plano Municipal de
Educação de Abaetetuba, a partir da seguinte ordem: a) Educação Infantil; b) Ensino Fundamental; c) Educação de Jovens e Adultos; d) Educação Especial; e) Educação do Campo; f) Formação e Valorização dos Profissionais da Educação; g) Financiamento e Gestão Democrática da Educação.

Assim, constatamos a maneira como a Educação do Campo vai se tornando uma questão importante e se incluindo na pauta das políticas de educação locais, passando a ser constituída como política efetiva do município, sendo incluída na discussão do Plano Municipal de Educação, como um avanço significativo, que possibilitou a reflexão sobre a importância de se promover educação diferenciada para os territórios rurais. $\mathrm{O}$ texto do Plano Municipal de Educação de Abaetetuba expressa essa situação,

A falta de sintonia da política de educação que historicamente tem desconsiderado a realidade do campo tem gerado vários questionamentos quanto à função da escola formal em relação ao contexto dos povos que vivem no campo. Estes questionamentos passam a surgir exatamente pela necessidade de se buscar uma alternativa que possa garantir o acesso, permanência e a formação para o desenvolvimento do meio em que vivem esses sujeitos, que têm buscado caminhar na direção de uma formação de qualidade adequada a sua realidade, buscando compreender os problemas encontrados no campo, para então 
explicar os fenômenos científicos, resultando em novos conhecimentos integrados com formação geral no contexto do campo.

Desta forma, vai se tornando mais clara a necessidade das escolas do campo do município de Abaetetuba assumirem, urgentemente, um currículo voltado para o atendimento educacional em conformidade e sintonizado com os saberes e fazeres cotidianos dos sujeitos do campo, considerando seus modos de vida e de trabalho, e tornando os sujeitos do campo como os principais construtores de um modelo político educacional que atenda as suas reais necessidades.

Outro aspecto importante a considerar foi a adesão, no mesmo ano de 2011, por parte da Secretaria Municipal de Educação de Abaetetuba, ao Programa Projovem Campo - Saberes da Terra, que visa proporcionar o ingresso de jovens e adultos do campo ao ensino gratuito e obrigatório, enfatizando na formação por meio da Pedagogia da Alternância, desenvolvida através do Tempo Escola e do Tempo Comunidade. O tempo escola inclui os momentos formativos em sala de aula, enquanto o tempo comunidade se desenvolve por meio de estudos e pesquisas na própria comunidade onde os estudantes vivem. Segundo Canali (2007, p. 32, grifo no original), "O princípio da alternância contempla dois momentos imbricados: o tempo-escola, que consiste em estudos desenvolvidos nos centros de formação, e o tempo-comunidade, que oportuniza o desenvolvimento de estudos na comunidade".

\section{O Programa Projovem Campo -} Saberes da Terra é constituído pela Lei $\mathrm{N}^{\circ}$ 11.692, de 10 de junho de 2008 que regulamenta o seu funcionamento, o artigo 15 do dispositivo determina que

O Projovem Campo - Saberes da Terra atenderá a jovens com idade entre 18 (dezoito) e 29 (vinte e nove) anos, residentes no campo, que saibam ler e escrever, que não tenham concluído o ensino fundamental e que cumpram os requisitos previstos no art. $3^{\circ}$ da Lei no 11.326 , de 24 de julho de 2006.

No município de Abaetetuba, cerca de 166 alunos foram matriculados no Programa, compondo cinco turmas que funcionaram aos finais de semanas, com um total de 15 professores e 02 técnicos agropecuários. A duração do Programa foi de dois anos e carga horária total de $2400 \mathrm{~h}$ dividida por meio do Tempo Escola: $1800 \mathrm{~h}$ e Tempo Comunidade: $600 \mathrm{~h}$. O Projeto Político Pedagógico do Programa (2010, p. 29) trás como objetivo,

Desenvolver políticas públicas de Educação do Campo e de Juventude que oportunizem a jovens agricultores(as) familiares excluídos do sistema formal de ensino a 
escolarização em Ensino Fundamental na modalidade de Educação de Jovens e Adultos, integrado à qualificação social e profissional.

Nossos estudos constataram a inclusão social de muitos jovens e adultos abaetetubenses no ensino fundamental por meio do Programa Saberes da Terra, resgatando o direito ao acesso a uma educação de nível fundamental articulada à qualificação profissional, uma demanda hoje contínua dos povos do campo, que possibilita a vinculação das ações de elevação de escolaridade com a formação profissional na Educação Básica.

Desta forma, observa-se que os debates políticos sobre Educação do Campo que foram mobilizados pelos movimentos sociais tanto em nível nacional como regional, estadual e local tiveram desdobramentos positivos no cotidiano das ações e políticas para os territórios rurais, pois os sujeitos do campo, das águas e da floresta do município de Abaetetuba foram beneficiados com as conquistas realizadas por esses movimentos em termos de Educação Básica e Superior pública para o campo.

Constatou-se por meio desse estudo que as políticas públicas de Educação do Campo que emergem no contexto social do município de Abaetetuba são resultantes das mobilizações e das demandas sociais que integram o FORECAT.

\section{Considerações finais}

O conjunto de reflexões por nós realizado, ao $\log$ o do artigo, nos oportunizou concluir que o processo de exclusão social é visível na realidade brasileira, principalmente no que se refere ao fator educacional, uma vez que a educação, em épocas passadas, tinha como objetivo atender apenas aos filhos das classes dominantes, não existindo escolas para atender os trabalhadores $\mathrm{e}$ trabalhadoras. Esse processo de exclusão tem impulsionado a criação de organizações que se mobilizam e lutam pelo interesse dos trabalhadores, como é o caso dos movimentos sociais.

Os fatos por nós observados e analisados oportunizam a constatação de que ao longo dos anos os sujeitos do campo em suas inúmeras lutas têm obtido conquistas significativas, devido suas ações coletivas, as quais vêm se desdobrando na garantia do acesso a uma educação com qualidade. No entanto, é de conhecimento público que nem sempre foi assim, pois esbarramos ainda na burocracia estatal, que limita e regula as ações demandadas e reivindicadas pelos movimentos sociais do campo. 
Paulo Freire (1996, p. 54) em suas reflexões nos anima a não nos conformar com esses obstáculos quando afirma: “Afinal, minha presença no mundo não é a de quem a ele se adapta, mas a de quem nele se insere. É a posição de quem luta para não ser apenas objeto, mas sujeito também da História ... sei também que os obstáculos não se eternizam”.

A pesquisa realizada apontou que as políticas de Educação do Campo que no período mais recente estão surgindo tanto em nível nacional como estadual e local, especialmente no município de Abaetetuba são resultantes das demandas e mobilizações dos movimentos sociais de representatividade dos sujeitos do campo.

Em nível nacional apontamos a conquista das "Diretrizes Operacionais para a Educação Básica nas Escolas do Campo. Resolução ${ }^{\circ} 1$, de 3 de Abril de 2002"; a aprovação do "Decreto n' 7. 352, de 4 de novembro de 2010 que dispõe sobre a política de educação do campo e o Programa Nacional de Educação na Reforma Agrária - PRONERA” e da "Resolução n" 2, de 28 de abril de 2008 que Estabelece diretrizes complementares, normas e princípios para o desenvolvimento de políticas públicas de atendimento da Educação Básica do Campo".
Em se tratando de conquista de políticas públicas local, o FORECAT foi um ator fundamental que influenciou na criação da Coordenação de Educação do Campo no município de Abaetetuba, na inserção das referências sobre Educação do Campo no Plano Municipal de Educação do Município, na adesão ao Programa Projovem Campo - Saberes da Terra, que oportuniza o ingresso de jovens e adultos agricultores familiares na educação de jovens e adultos com qualificação profissional, sendo este o objetivo do Programa.

Outro aspecto importante em relação ao FORECAT refere-se aos vários eventos promovidos na Região do Baixo Tocantins, que pautam especificamente a Educação do Campo e envolve a participação ampliada de múltiplas instituições, entidades, educadores e sujeitos do campo, das águas e da floresta em seminários, encontros e reuniões do Fórum, dentre outras atividades.

Em Abaetetuba, na atualidade, com a força do movimento social do campo que integra o FORECAT e das entidades e instituições envolvidas com os territórios rurais, um novo horizonte está sendo desenhado em se tratando de políticas públicas para a Educação do Campo, indicando que o cenário da Educação do Campo no referido município vem se 
afirmando e ampliando a participação dos sujeitos individuais e coletivos mediante as ações implementadas.

Neste cenário, é de fundamental importância que a construção de uma escola com a participação da comunidade escolar, de um conselho sério, ativo e dinâmico, com propostas pedagógicas decisivas e a participação dos educandos na gestão escolar; pois ainda hoje em nosso país vivemos à mercê de um sistema educacional precário e lento, que impõe restrições às ações dos educadores e educandos nas escolas do campo.

No caso do município de Abaetetuba, o estudo que realizamos indicou que o quadro da educação vem sendo alterado positivamente face ao compromisso daqueles que não medem esforços para conquistar uma educação do campo sintonizada com as especificidades e os anseios dos povos do campo, das águas e da floresta, em que se incluem os movimentos sociais e as entidades, instituições e atores coletivos e individuais que integram o FORECAT.

Portanto, se nossa intenção é fortalecer a Educação do Campo no município de Abaetetuba, faz-se necessário refletirmos sobre a dinâmica do movimento de culturas, de saberes, sobre os modos de vida e de trabalho que são constituintes das relações sociais que se estabelecem nos territórios rurais. Nada melhor que fortalecer o protagonismo desses sujeitos individuais e coletivos como ponto de partida para o debate por um projeto político educacional que contemple toda a diversidade do saber fazer do cotidiano dos povos do campo do referido município.

\section{Referências}

Arroyo, M. G., Caldart, R. S., \& Molina, C. M. (2004). Apresentação. In Arroyo, M. G., Caldart, R. S., \&, Molina, M. C. (Orgs). Por uma educação do campo. Petrópolis, RJ: Vozes.

Bagno, M. (2007). Nada na Língua é por Acaso: Por uma pedagogia da variação linguística. São Paulo: Parábola Editorial.

Barros, F. B. (2009). Sociabilidade, cultura e biodiversidade na Beira de Abaetetuba no Pará. Revista Ciências Sociais Unisinos, 152-161.

Brasil. (1988). Senado Federal. Constituição da República Federativa do Brasil. Brasília, Centro Gráfico.

. (2002). Diretrizes Operacionais para a Educação Básica nas Escolas do Campo. Resolução $\mathrm{n}^{\circ} 1$, de 3 de Abril de 2002.

(2008). Diretrizes complementares, normas e princípios para o desenvolvimento de políticas públicas de atendimento da Educação Básica do Campo. Resolução $\mathrm{n}^{\mathrm{o}} 2$, de 28 de abril de 2008. 
junho de 2008 .

(2008). Lei $\mathrm{n}^{\circ} 11.692$, de 10 de (2010). Dispõe sobre a política de educação do campo e o Programa Nacional de Educação na Reforma Agrária - PRONERA. Decreto no 7. 352, de 4 de novembro de 2010.

(2010). Instituto Brasileiro de Geografia e Estatística (IBGE).

(2010). Projeto Político Pedagógico: Programa Nacional de Educação de Jovens e Adultos Integrada com qualificação Social e Profissional para Agricultores (as) familiares. Brasília.

. (2011). Secretaria Municipal de

Educação de Abaetetuba (SEMEC) Regimento da Conferência Municipal de Educação para a Aprovação do Plano Municipal de Educação de Abaetetuba.

. (2012). Secretaria Municipal de

Educação de Abaetetuba (SEMEC) Relatório de dados.

Brito, D. M. (2005). A Educação rural no município de Abaetetuba- PA: As especificidades das turmas multisseriadas. In XVII EPENN - Encontro de Pesquisa Educacional Norte e Nordeste, Belém PA. Educação, Ciência e Desenvolvimento Social.

Caldart, R. S. (2004). A escola do campo em movimento. In Arroyo, M. G., Caldart, R. S., \& Molina, M. C. (Orgs). Por uma educação do campo. Petrópolis, RJ: Vozes.

Caldart, R. S. (2004). Elementos para a Construção do Projeto Político Pedagógico da Educação do Campo. In Contribuições para a Construção de um Projeto de Educação do Campo. Brasília-DF: Articulação Nacional por uma Educação do Campo.
Canali, H. H. B. (2007). Educação do Campo: Construindo novas referências. In Silva, G. P. et al. (Orgs). Educação do Campo na Amazônia: uma experiência. Belém: EDUFPA.

Ferreira, M. J. F. et al. (2010). Sociedade, Estado e Educação: ênfase nos governos municipais e educação do campo. In II Encontro de Pesquisa em Educação do Campo do Estado do Pará: Os Usos Políticos, sociais e acadêmicos dos Conhecimentos, suas tensões $e$ contribuições para a participação $e$ controle social. Belém.

Freire, P. (1996). Pedagogia da Autonomia: saberes necessários à prática educativa. São Paulo, Paz e Terra.

Gomes, M. S., Silva, G. P., \& Wanzeler, J. P. (2007). Um Olhar sobre a Educação do Campo a partir do Projeto Magistério da Terra Pólo Tucuruí. In Silva, G. P. et al. (Orgs). Educação do Campo na Amazônia: uma experiência. Belém: EDUFPA.

Gorgen, F. S. A. (2012). Agrocombustíveis. In Dicionário $d a$ Educação do Campo. Organizado por Roseli Salete Caldart, Isabel Brasil Pereira, Paulo Alentejano e Gaudêncio Frigotto. Rio de Janeiro, São Paulo: Escola Politécnica de Saúde Joaquim Venâncio, Expressão Popular.

Hage, S. M. (2005). A importância da articulação na construção da identidade e pela luta da educação do campo. Texto apresentado no I Encontro de Formação de Educadores do Campo do Nordeste Paraense.

(2005). GEPERUAZ: Aspectos significativos de sua criação, identidade e abrangência. In Hage, S. M. Educação do campo na Amazônia: retratos de realidade das escolas multisseriadas no 
Pará. Belém, Gráfica e Editora Gutemberg Ltda.

Leite, S. C. (1999). Escola Rural: urbanização e políticas educacionais. São Paulo, Cortez.

Machado, J. (2008). História de Abaetetuba: com referenciais na história social e econômica da Amazônia. Abaetetuba, Edições Alquimia.

Marques, M. O. (1992). A Formação do Profissional da Educação. Ijui, Ed. Unijui.

Molina, M. C., \& Freitas, H. C. A. (2011). Avanços e desafios na construção da Educação do Campo. Em Aberto, 24(85), 17-31.

Olinto, A. (2001). Minidicionário da Língua Portuguesa. São Paulo: Moderna.

Oliveira, D. A. (2011). Das Políticas de Governo a Política de Estado: reflexões sobre a atual agenda educacional brasileira. In Educ. Soc., 32(115), 323-337. Disponível em < http://www.cedes.unicamp.br/>

Pereira, J. R., \& Pereira, R. C. (2010). Políticas Públicas na Educação do Campo do Município de Abaetetuba-PA: Possibilitando o Diálogo com os Movimentos Sociais. (Trabalho de Conclusão de Curso). Universidade Federal do Pará, Abaetetuba.

Soares, M. (2002). Linguagem e Escola: uma perspectiva social. São Paulo: Ática.

Silva, R. V. M. (2004). O português são dois: novas fronteiras, velhos problemas. São Paulo: Parábola Editorial.

Teixeira, E. (1998). Políticas públicas no município - dificuldades e possibilidades da municipalização. CONTAG.
${ }^{\mathrm{i}}$ Conflitos de interesse: Salomão Hage é membro do Conselho Editorial Nacional da Revista Brasileira de Educação do Campo e não participou do processo de avaliação do manuscrito.

ii Sesmaria eram lotes de terras inculcadas que os Reis de Portugal cediam a quem se dispusessem a cultivá-las. (Machado, 2008, p. 7).

iii Serviço que se faz extraordinariamente e que dá pequenos lucros. (Olinto, 2001, p. 72).

Recebido em: 03/02/2017

Aprovado em: 09/04/2017

Publicado em: 29/06/2017

Como citar este artigo / How to cite this article / Como citar este artículo:

APA:

Pereira, R. C., Pureza, A. M. S., \& Hage, S. A. M. (2017). Educação do Campo e políticas públicas no município de Abaetetuba-Pará. Rev. Bras. Educ. Camp., 2(1), 364-388. DOI: http://dx.doi.org/10.20873/uft.25254863.2017v2n1p364

ABNT:

PEREIRA, R. C.; PUREZA, A. M. S.; HAGE, S. A. M. Educação do Campo e políticas públicas no município de Abaetetuba-Pará. Rev. Bras. Educ. Camp., Tocantinópolis, v. 2, n. 1, p. 364-388, 2017. DOI: $\underline{4863.2017 \mathrm{v} 2 \mathrm{n} 1 \mathrm{p} 364}$ 